\title{
Activation of mTOR coincides with autophagy during ligation-induced atrophy in the rat submandibular gland
}

\author{
N Silver ${ }^{1}, \mathrm{~GB}$ Proctor $^{1}, \mathrm{M} \mathrm{Arno}^{2}$ and GH Carpenter ${ }^{*, 1}$
}

Salivary gland atrophy is a common consequence of pathology, including Sjögren's syndrome, irradiation therapy and obstructive sialadenitis. During severe atrophy of the rat submandibular gland caused by excretory duct ligation, the majority of acinar cells disappear through apoptosis, whereas ductal cells proliferate and dedifferentiate; yet, the gland can survive in the atrophic state almost indefinitely, with an ability to fully recover if deligated. The control mechanisms governing these observations are not well understood. We report that $\sim 10 \%$ of acinar cells survive in ligation-induced atrophy. Microarray and quantitative real-time PCR analysis of ligated glands indicated sustained transcription of acinar cell-specific genes, whereas ductal-specific genes were reduced to background levels. After 3 days of ligation, activation of the mammalian target of rapamycin (mTOR) pathway and autophagy occurred as shown by phosphorylation of 4E-BP1 and expression of autophagyrelated proteins. These results suggest that activation of $\mathrm{mTOR}$ and the autophagosomal pathway are important mechanisms that may help to preserve acinar cells during atrophy of salivary glands after injury.

Cell Death and Disease (2010) 1, e14; doi:10.1038/cddis.2009.12; published online 21 January 2010

Subject Category: Experimental medicine

This is an open-access article distributed under the terms of the Creative Commons Attribution License, which permits distribution and reproduction in any medium, provided the original author and source are credited. This license does not permit commercial exploitation without specific permission.

Salivary glands are highly specialized exocrine organs secreting large amounts of protein and fluid. The two main cell types are acinar and ductal; acini generate the osmotic gradients that drive fluid secretion, and ductal cells modify the ionic composition by reabsorbing $\mathrm{NaCl}$ in exchange for potassium. Both acini and ductal cells can synthesize and secrete large amounts of proteins, but acinar cells typically produce most proteins. Protein synthesis seems to be governed largely by mRNA copy number, as most mRNAs are for secretory proteins. Autonomic nerves closely control levels of protein synthesis, ${ }^{1}$ so that feeding (when large amounts of proteins are secreted into saliva) drives protein synthesis to replenish stored proteins. Most secretory proteins are stored in granules, ${ }^{2}$ although constitutive secretion of proteins occurs in the absence of overt stimulation. ${ }^{3}$

Atrophy of salivary glands in humans can occur because of a number of different conditions, including Sjögren's syndrome, irradiation therapy and obstructive sialadenitis. The understanding of salivary gland atrophy and its reversal through regeneration is clinically important because salivary secretion is vital for protection of the oral environment. Obstructive sialadenitis can be mimicked experimentally in the rat by ligation of the main excretory duct of the submandibular gland, producing a histological appearance comparable with, although more widespread than, that which occurs in human disease. ${ }^{4}$ This includes deletion of acinar cells through apoptosis, ${ }^{5}$ necrosis and autophagy, ${ }^{6}$ as well as dedifferentiation and mitotic proliferation of ductal cells. ${ }^{5}$ Atrophy also occurs when neural input is reduced. ${ }^{7,8}$ Parasympathetic denervation causes a gradual loss of secretory granules and then acinar morphology. Sympathectomy again causes a modest reduction in gland weight $(\sim 10 \%)$ over a period of several weeks. ${ }^{9}$ In contrast, the ligation-induced atrophy described in this study results in a rapid weight loss of up to $50 \%$ within 1 week, as well as in the complete loss of secretory granules from acinar and ductal cells. ${ }^{10,11}$ Thus, nerve sectioning may be considered as a disuse atrophy, whereas ligation-induced atrophy seems to be an active process. In this study, we investigated the relationship between changes in gene expression and histopathology in a time course of ligation-induced atrophy and possible mechanisms of control.

One potentially important mechanism of regulating gene expression is through the $\mathrm{PI} / 3 \mathrm{k} / \mathrm{Akt}$ pathway ${ }^{12}$ and its downstream target - the mammalian target of rapamycin (mTOR). This highly conserved serine/threonine protein kinase is essential for control of cell growth and proliferation in response to cell stress, growth factors and nutrients. ${ }^{13,14}$ It has an important role in the regulation of atrophy of both skeletal muscle and liver tissue. ${ }^{15}$ mTOR is likely to be instrumental in the cell-specific control of many submandibular acinar and ductal proteins during atrophy and this can

\footnotetext{
${ }^{1}$ Salivary Research Unit, Floor 17 Tower Wing, King's College London, Dental Institute, London, UK and ${ }^{2}$ Genomics Centre, Kings College London, London, UK *Corresponding author: GH Carpenter, Salivary Research Unit, Floor 17 Tower Wing, King's College London, Dental Insitute, London SE1 9RT, UK. Tel: + 020718874 60; E-mail: guy.carpenter@kcl.ac.uk

Keywords: atrophy; mTOR; autophagy; submandibular gland

Abbreviations: AB/PAS, Alcian Blue/periodic acid-Schiff's; mTOR, mammalian target of rapamycin; AQP5, aquaporin 5; TON, tonin; SMR2, submaxillary gland androgen regulated protein 2; 4E-BP1, eukaryotic initiation factor 4E-binding protein 1; LC3, light chain 3; Q-RT-PCR, quantitative real-time polymerase chain reaction Received 06.10.09; revised 09.11.09; accepted 09.11.09; Edited by G Melino
} 
be attributed, in part, to two types of mechanistic pathways. The first involves the binding protein 4E-BP1 (eukaryotic translation initiation factor 4E binding protein 1), which, when phosphorylated, allows translation by dissociating from elF-4E. ${ }^{16}$ The second pathway involves the control of autophagy, the sequestration of cellular material for destruction by the lysosomal compartment. Characteristic doublemembrane autophagic vacuoles are seen in electron microscopical studies of ligation-induced atrophy and in starvation studies of rat salivary glands. ${ }^{11,17}$ The molecular processes involved in autophagy are beginning to be unraveled and involve conjugation of microtubule-associated protein 1 light chain 3 (MAP-LC3/Atg8/LC3) to phosphatidylethanolamine (PE). ${ }^{18}$ LC3 (cytosolic) is cleaved at its $C$ terminus by Atg4 to form LC3-I, which is covalently conjugated to PE by Atg3 catalysis to form LC3-II. Thus, conversion of LC3-I to LC3-II (membrane associated) ${ }^{18}$ by Atg 3 is a useful marker for autophagy.

In this study, we show that in ligation-induced atrophy, although the transcription of ductal genes such as kallikreins is quickly turned off, many acinar-specific genes are expressed at high levels. Low expression of acinar proteins during ligation, including aquaporin 5 (AQP5), a water channel that has a significant role in salivation, ${ }^{19}$ and SMR2, a major salivary secretory glutamine/glutamic acid-rich protein, ${ }^{20}$ seems to be the result of autophagosomal routing. The activation of mTOR at the same time point as apoptosis ${ }^{5}$ and autophagy may be a survival mechanism for the remaining acinar cells. Therefore, there seems to be a strong association and a high degree of coordination between these two pathways in the progression of submandibular gland atrophy and survival.

\section{Results}

Gland weights and histology. After 1 day of ligation, submandibular glands weighed $>30 \%(P=<0.04)$ heavier than unoperated controls (Figure 1a). From 3 days of ligation onward, gland weights decreased, and after 2 weeks of ligation, they weighed $<50 \%(P<0.007)$ of controls. The increased weight of the 1-day ligated glands was accompanied by altered histology (Figure $1 \mathrm{~b}$ and $\mathrm{c}$ ). Oneday ligated glands contained large numbers of infiltrating inflammatory cells (Figure 1c, arrow) that were most prominent in the gland stroma but also present within the interstitial spaces (Figure 1c, arrow head) between acini and ductal structures, and were mostly neutrophils and macrophages (based on cell size and shape). At 3-5 days of ligation (Figure 1d-e), a relative reduction in inflammatory cell infiltration is seen when compared with 1-day ligated glands. A significant loss in secretory proteins from acinar and ductal cells was seen, as indicated by reduced blue/ purple staining from acinar cells and pink staining from ductal cells. By day 7 of ligation, acinar cells were unidentifiable, with an almost complete absence of secretory granules (Figure 1f). Staining of the 9- and 14-day ligated glands suggested that acini had almost completely disappeared (Figure $1 \mathrm{~g}$ and $\mathrm{h}$ ), as their usual features (such as large volume, secretory granules, basolateral nuclei) were no longer obvious. However, although most acini had disappeared, as indicated by the presence of secretory protein, a small sub-population of acinar cells along the periphery of the gland remained (Figure 1h, arrow head). Duct-like structures were still visible, with the presence of some secretory products in the lumen of the ducts (Figure $1 \mathrm{~g}$ and $h$, arrows), but were not the usual differentiated types (granular, striated or intercalated).

\section{Alterations in transcription and translation of salivary} proteins. Microarray analyses of control and 14-day ligated glands ( $n=3$ for both groups) revealed an altered expression of 1567 probe sets. A total of 1083 genes were upregulated, 484 were downregulated and the remaining genes on the chip showed either no statistically significant change in expression between experimental conditions or were not expressed. Expression of genes specific to ductal cells, particularly granular ducts, was often very highly expressed in the normal tissue but was almost undetectable by 14 days of ligation. Table 1 shows a selection of these ductal markers. One of the most striking changes in gene expression observed was for tonin (TON), a major secretory (within the top $1 \%$ of greatest expression of whole-glandular genome - results not shown) tissue kallikrein in granular ductal cells, and quantitative real-time PCR (Q-RT-PCR) confirmed the decreases (Figure $2 a$ and b). Decreased TON protein expression was also indicated by $p$-dimethylaminobenzaldehyde (DMAB) staining (Figure 2c and d).

In contrast to ductal cell-specific genes, few acinar-specific genes showed significant changes by microarray analyses. Table 2 shows a selection of typical acinar cell markers (and within the top 1\% of gene expression). Two genes from this list, which were further studied to confirm these observations, were $A Q P 5$, a water channel and SMR2, a major glutamine/glutamic-rich salivary protein. Unlike microarray analyses, Q-RT-PCR indicated a statistically significant decrease of 14-fold for AQP5 and 94-fold for SMR2 in the 2-week ligated glands relative to controls (Figure $3 a$ and $b$ ). Despite significant decreases, residual mRNA levels after 2 weeks of ligation were still considerably greater than that of background and still easily detected (Figure $3 a$ and b). Although AQP5 showed relatively high transcript levels when compared with background, immunofluorescence detection of AQP5 protein (Figure $3 c-g$ ) was sparse by day 14 of ligation, comparable with background fluorescence (Figure 3g).

Detection of residual acinar cells after ligation. As suggested by AB/PAS histology (Figure $1 b-h$ ), most acinar characteristics were no longer apparent in 2-week ligated (atrophic) glands. As this apparent loss of acinar cells in the 2-week ligated glands did not correspond to continued expression of measured acinar cell transcript levels, further investigations attempted to establish whether significant numbers of active acinar cells were still present in the atrophic gland.

In normal submandibular glands, myoepithelial cells (containing smooth muscle actin) encompass acinar cells, and are thus useful in the identification of acinar cells in ligated glands in which the usual acinar characteristics are lost. As 


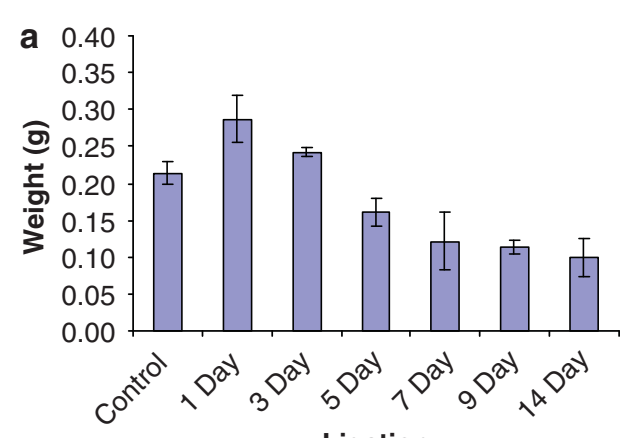

5 day ligated

\section{Normal}

\section{Ligation}

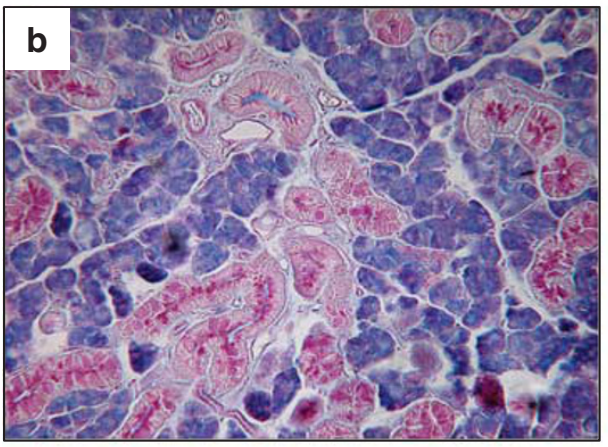

\section{$24 \mathrm{hr}$ ligated}

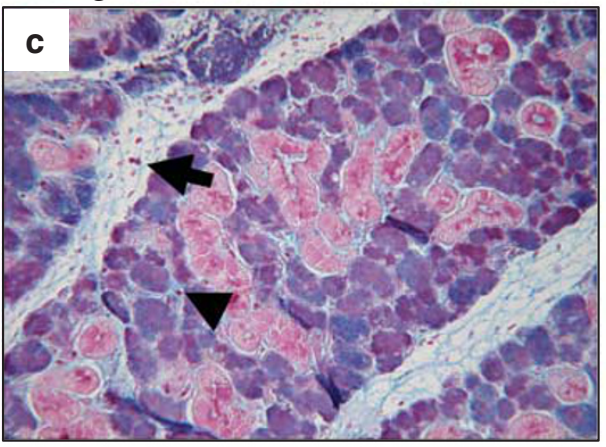

3 day ligated
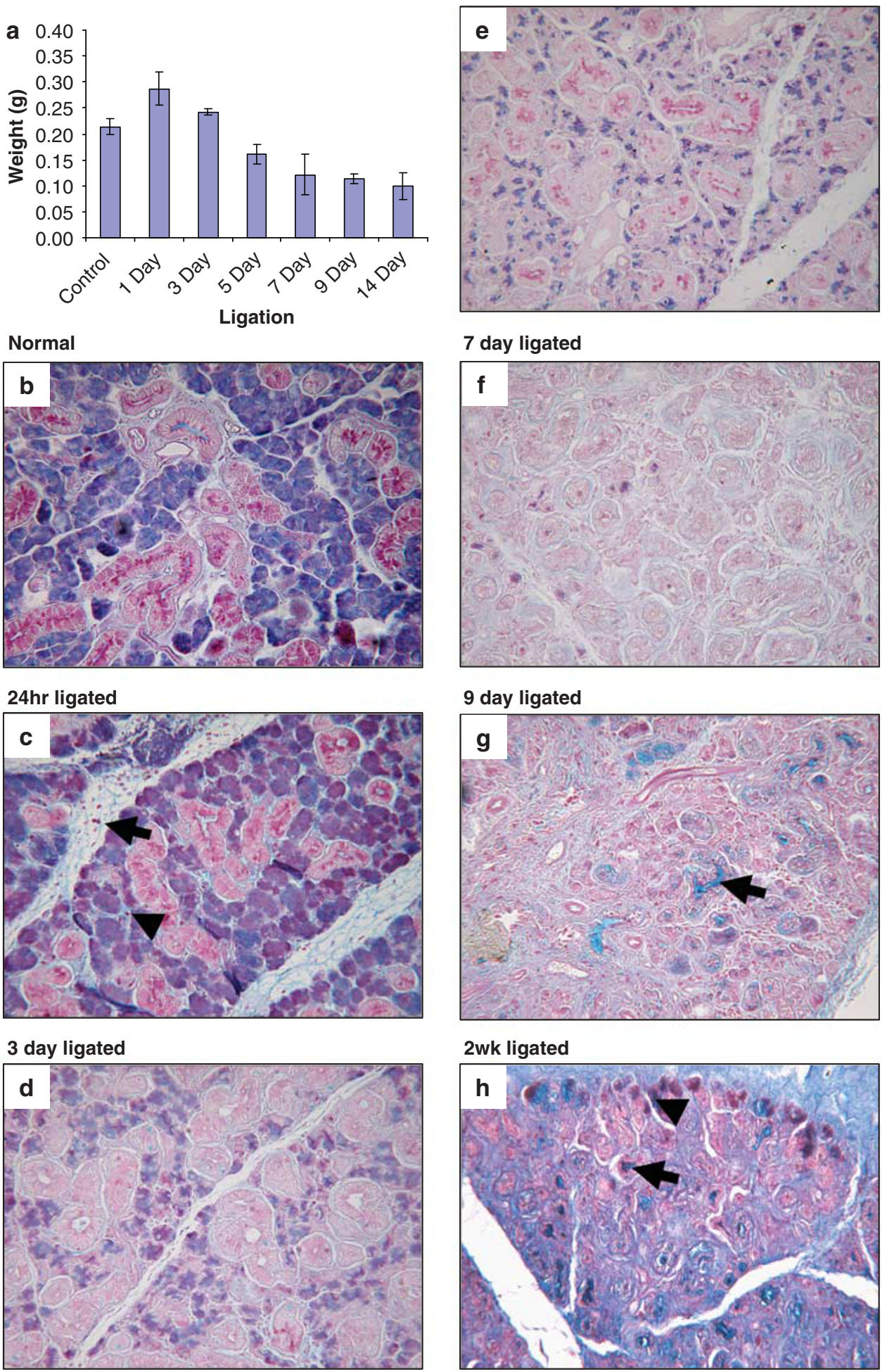

\section{7 day ligated}

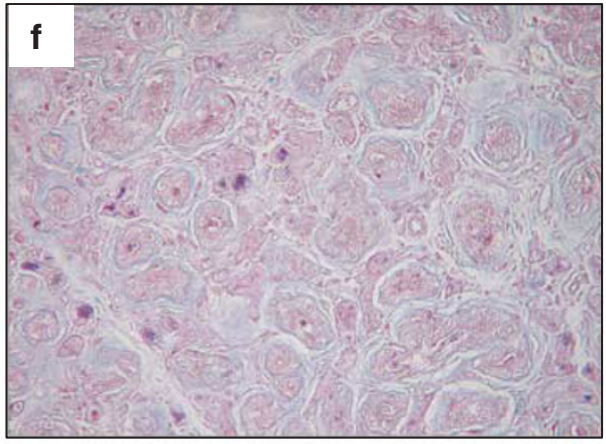

\section{9 day ligated}

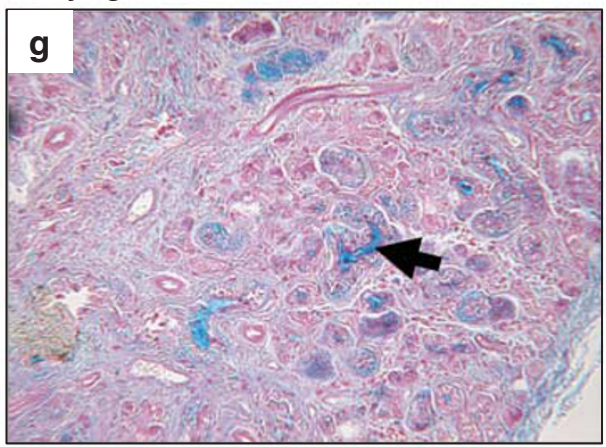

\section{2wk ligated}

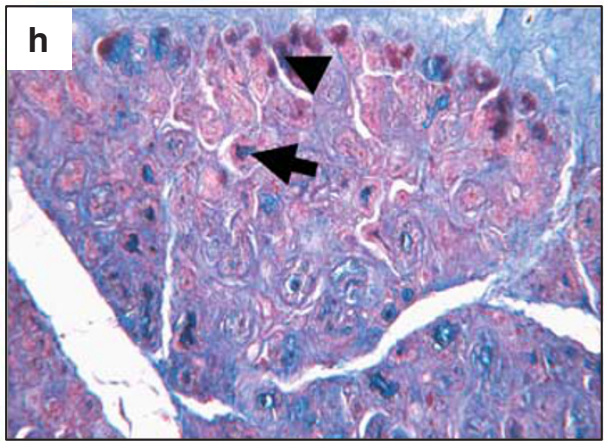

Figure 1 Gland weights (a) and Alcian Blue/PAS staining $(\mathbf{b}-\mathbf{h})$ of submandibular glands with increasing periods of ligation. (Panel a) Mean weight \pm S.D. of glands after $0,1,3,5,7,9$ and 14 days of ligation. $n=3$ for all time points. (Panel b) Control: unoperated submandibular gland showing the typical appearance of acini (purple) and ductal (pink) cells. (Panel c) In 1-day ligated: large numbers of inflammatory cells invaded the stroma and interstitial spaces (arrows). (Panels $d$ and e) In 3-5-day ligated: considerable reduction of secretory proteins was seen. (Panel f) In 7-day ligated: little staining of secretory protein was apparent. (Panel g) In 9-day ligated: luminal dilation of ducts (arrow) shows some blue staining. (Panel h) In 14-day ligated: sub-population of acinar cells (arrow head) along the periphery of the gland continues to show the presence of secretory protein 
Table 1 Identification of ductal cell-specific genes that are highly expressed in unoperated control glands, but then subsequently downregulated in the 2-week ligated (atrophic) glands ( $n=3$ for both groups)

\begin{tabular}{lll}
\hline Accession no. & Ductal gene description & Functional category \\
\hline BI279260 & EST: Highly similar to glandular kallikrein 10 precursor & Kallikrein-like serine proteases \\
NM_012593.1 & Kallikrein 7, renal/pancreas/salivary (KIk7) & Serine protease family \\
BI279353 & EST: (clone RSKG50) kallikrein mRNA, 3 end kallikrein 3 & Serine protease family \\
NM_012677 & Tonin (Ton) (alias KIk2) & Kallikrein subfamily \\
M11566 & Submaxillary gland S3 kallikrein mRNA (KIks3) & Serine protease family \\
NM_012842 & Epidermal growth factor (Egf) & Growth Factor \\
Al169562 & EST: (clone K-32) kallikrein mRNA, 3 end (RGD:735228) & Serine protease family
\end{tabular}
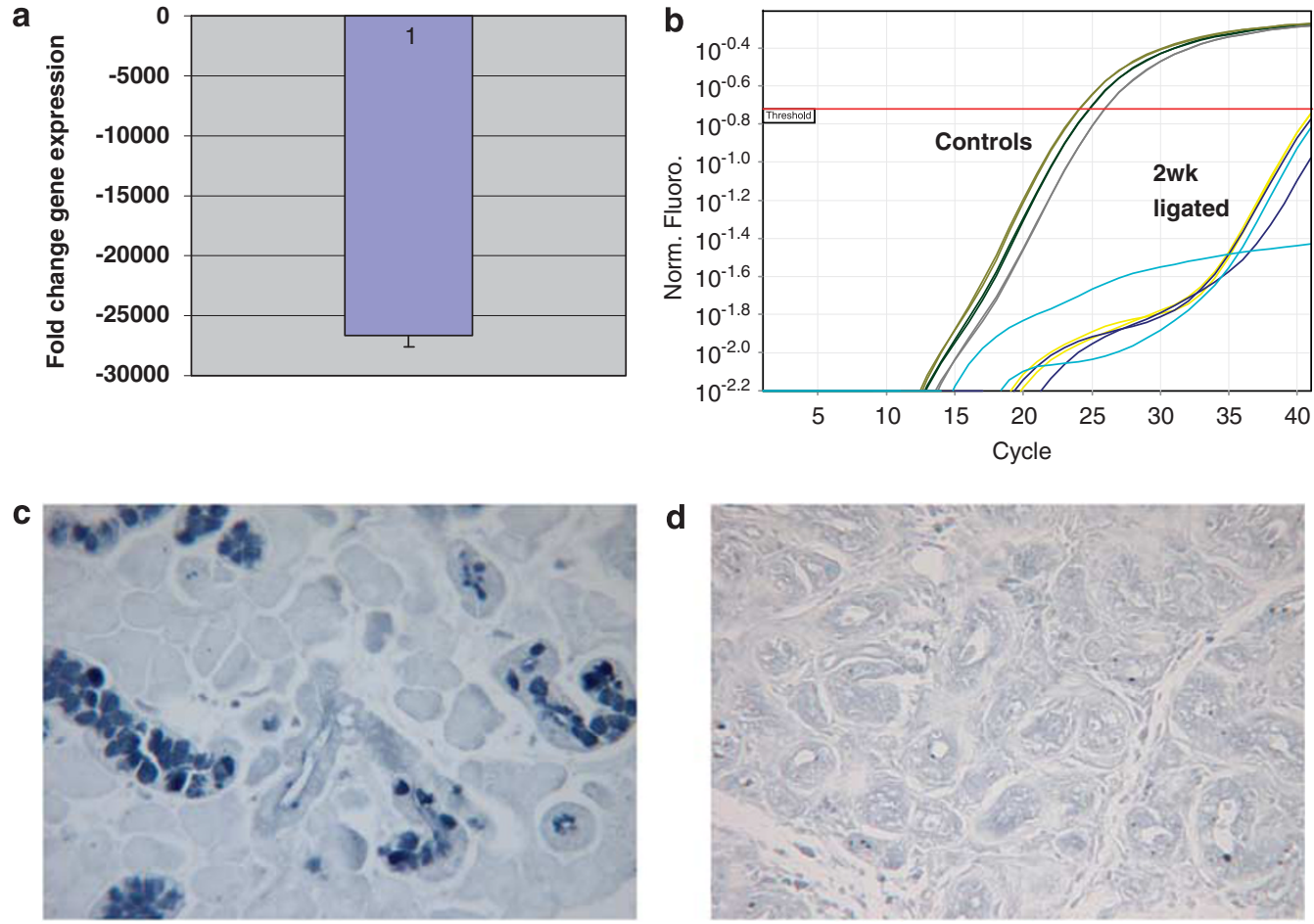

Figure 2 Expression of TON transcript and its corresponding protein tonin. (a) TON gene expression was measured by Q-RT-PCR, normalized to UBC and expressed as fold change. Q-RT-PCR indicated that TON was downregulated by $\sim 27000$-fold (background levels) in 2-week ligated glands $(n=3)$ when compared with controls $(n=3)$. (b) Raw unnormalized Q-RT-PCR data show the extent of TON downregulation. (c) DMAB (p-dimethylaminobenzaldehyde) dark blue staining of granular ducts in unoperated submandibular gland indicates the presence of tonin and other kallikreins. (d) Two-week ligated submandibular gland. DMAB staining showed degranulation of ducts and a complete loss of tonin protein expression

Table 2 Identification of highly expressed acinar cell markers that showed no change in expression between experimental conditions (control versus 2-week ligated)

\begin{tabular}{|c|c|c|c|}
\hline Accession no. & Acinar gene description & Functional category & $\begin{array}{l}\text { Fold } \\
\text { change }\end{array}$ \\
\hline Al104151 & Golgi SNAP receptor complex member 1 & Secretory granule secretion & NC \\
\hline M58654.1 & Glutamineglutamic acid-rich protein isoform $\mathrm{Cb}$ (GRP-Cb) & Secretory protein & NC \\
\hline $\mathrm{BI} 279097$ & CAH6 mouse carbonic anhydrase VI precursor (M.musculus) & Secretory protein & NC \\
\hline NM_022708.1 & Rattus norvegicus prolactin-inducible protein (Pip) & Secretory protein & NC \\
\hline M63112.1 & Variable coding sequence A1 (Vcsa1) (androgen-regulated protein (SMR1) gene) & Secretory protein & NC \\
\hline NM_133513.1 & Mucin 10, submandibular gland salivary mucin (Muc10) & Secretory protein & NC \\
\hline J05491 & Submaxillary gland androgen-regulated protein 2 (SMR2) & Secretory protein & NC \\
\hline NM_012779.1 & Aquaporin 5 (Aqp5) & Water channel & NC \\
\hline
\end{tabular}

NC, no change.

myoepithelial cells also surround ductal structures in atrophic glands, ${ }^{21}$ structures with an obvious lumen were excluded (Figure 4) from estimates of acinar cell number. When compared with normal unoperated glands (Figure 4a), 2-week ligated glands showed an almost complete loss of acinar cells and an increase in staining of shrunken ducts and 

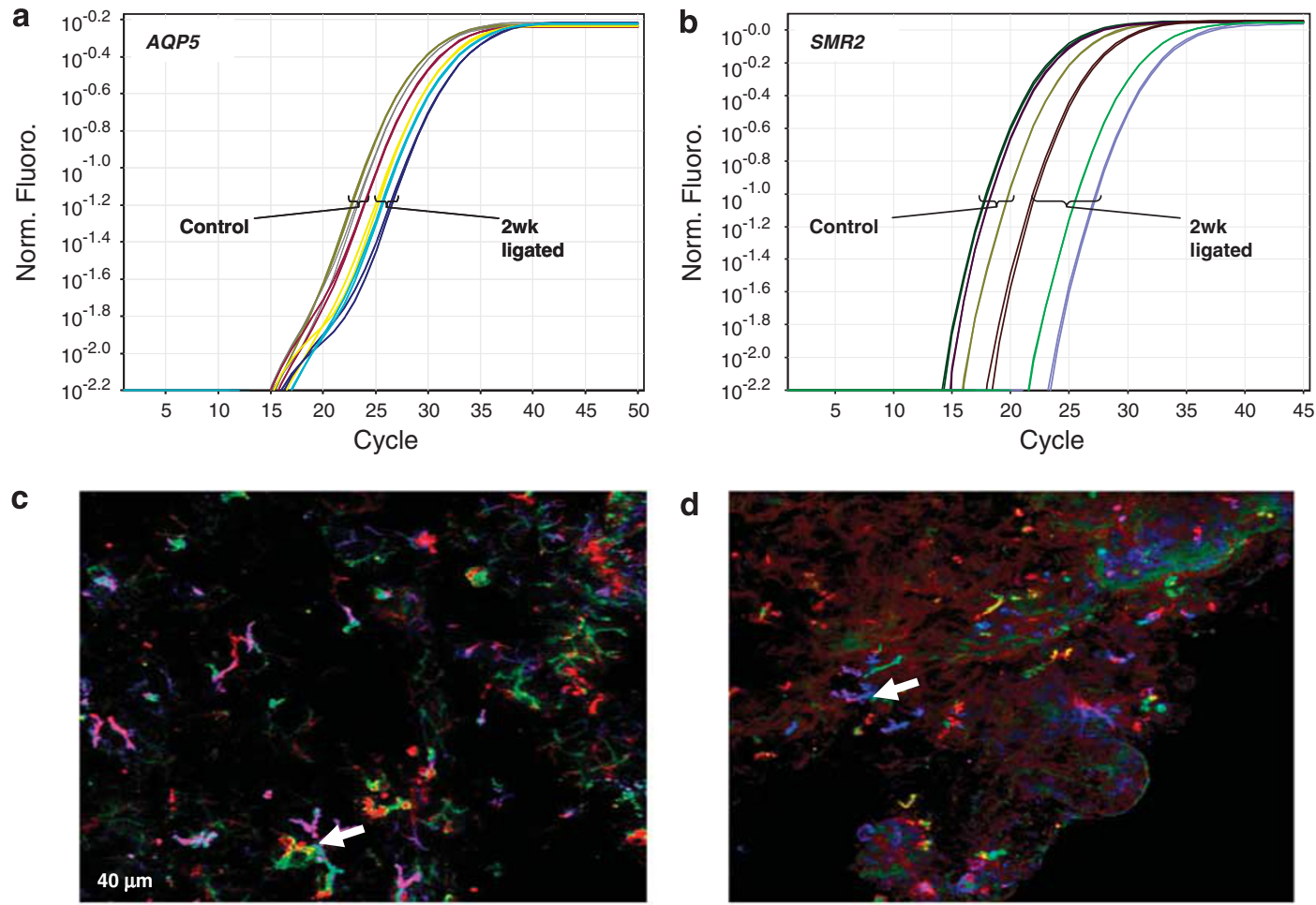

d

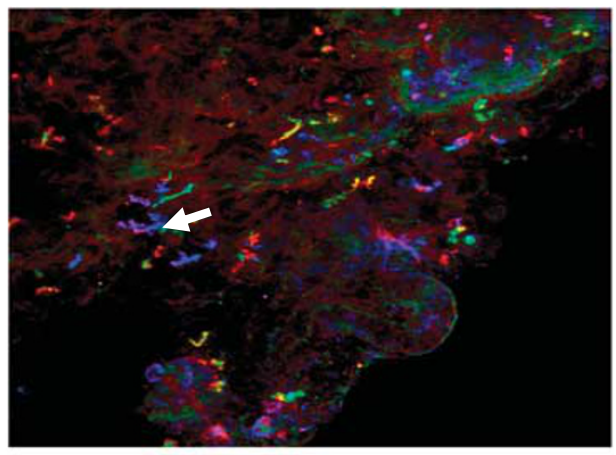

e
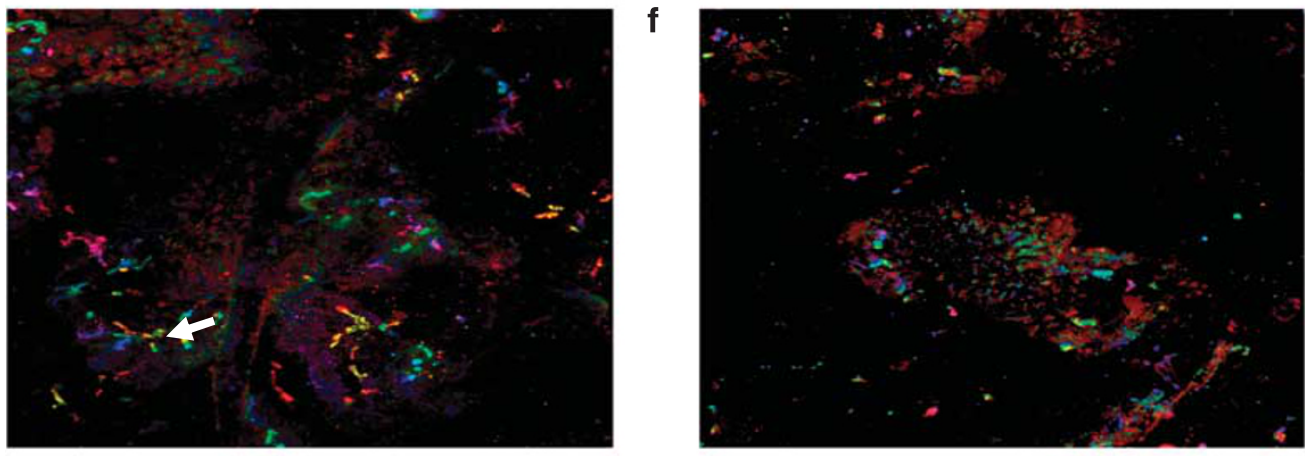

g

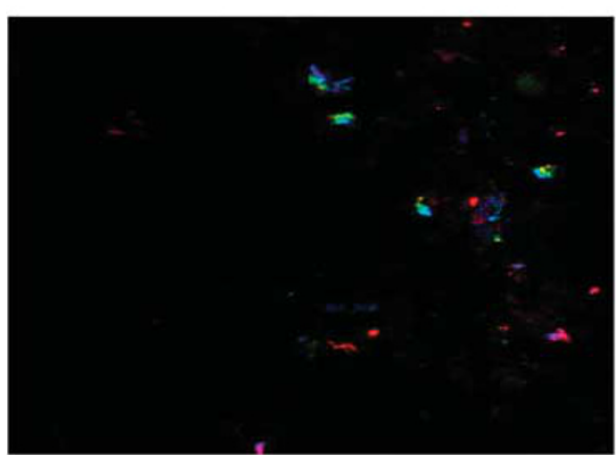

Front Back

Figure 3 Gene and protein expression of acinar cell products. (a, b) Raw unnormalized Q-RT-PCR data demonstrate that gene expression for both AQP5 (panel a) and SMR2 (panel b) remains relatively high (in terms of cycle numbers) after 2 weeks of ligation. (c-g) Combined Z-stack of AQP5 immunofluorescence. Collagenase-digested cells were incubated with an anti-AQP5 antibody and viewed by confocal microscopy. Z-stacks were reconfigured and pseudo-colored, wherein different colors represent different depths of field. (Panel c) Control: unoperated submandibular gland showing AQP5 is expressed along the apical membrane of acinar cells (arrow). (Panels $\mathrm{d}$ and e) In 3- and 5-day ligated: AQP5 expression is reduced; however, luminal networks are still visible (arrows). (Panel f) In 7-day ligated: has little luminal AQP5 staining. (Panel g) In 2-week ligated: only background fluorescence was detected 

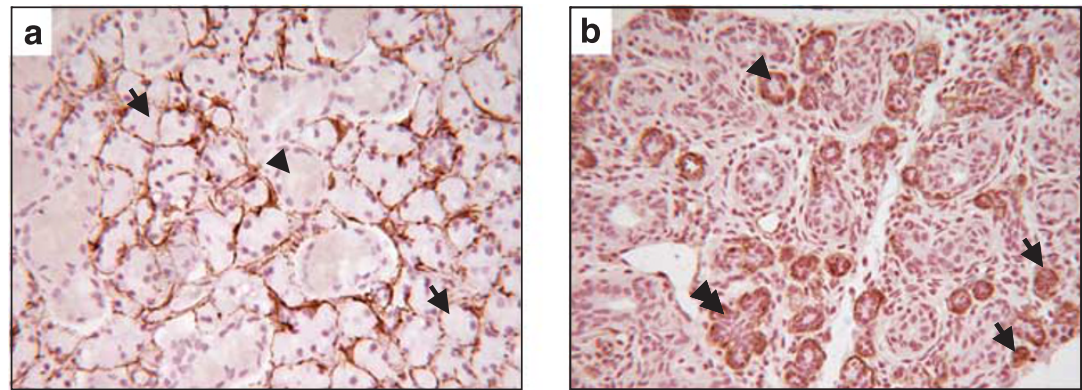

Figure 4 Smooth muscle actin immunohistochemistry on tissue sections. (a) Control: unoperated submandibular gland showing the typical appearance of acini (arrows) surrounded by immunopositive (brown staining) myoepithelial cells. In contrast, ductal structures (arrow head) are not stained. (b) Two-week ligated submandibular gland: smooth muscle actin staining showed the presence of residual acinar cells (arrows) as small groups of cells with positive staining. In addition, some ducts (arrow head) and ductal branch structures (double arrow head) were also stained

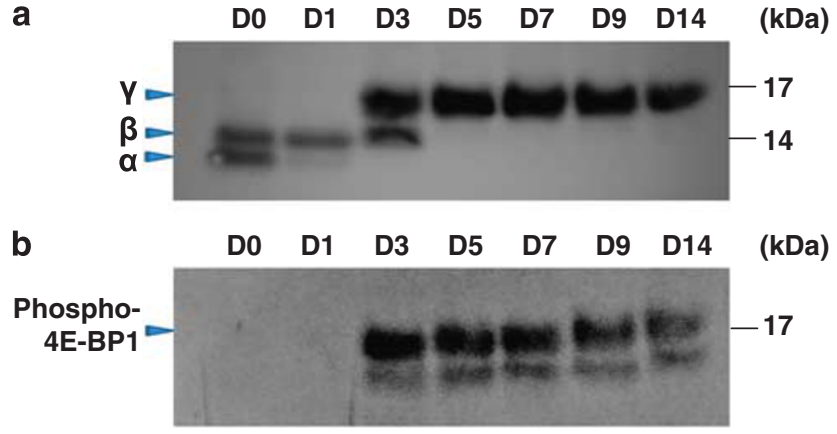

Figure 5 4E-BP1 protein expression in submandibular glands during progressively longer periods of ligation. Total protein abundance (a) and phosphorylation status (b) of 4E-BP1 protein was measured in homogenates of unoperated control (D0), 1 day (D1), 3 days (D3), 5 days (D5), 7 days (D7), 9 days (D9) and 14 days (D14) after duct ligation. Molecular weight ( $\mathrm{kDa}$ ) is indicated on the right of the diagram, whereas $4 \mathrm{E}-\mathrm{BP} 1$ isoforms $\alpha, \beta$ and $\gamma$ are indicated on the lefthand side. These blots are representative of two other series of samples

branch-like duct structures (Figure 4b). However, small welldefined groups of cells without an obvious lumen were present, suggesting the presence of residual acinar cells. The numbers of these acinar cells in three sections from three different glands for control $(n=68$, S.D. \pm 8$)$ and 2-week ligated glands $(n=7, \pm 3)$ suggested that only $10 \%$ of acinar cells remain $(P=<0.004)$.

\footnotetext{
Activation of the mTOR pathway during ligation-induced atrophy. Expression of the 4E-BP1 protein in submandibular gland homogenates was investigated at different stages of ligation. Three isoforms were found (Figure 5a). On the basis of their molecular weight, these were identified as isoforms $\alpha, \beta$ and $\gamma ; \alpha$ represents 4E-BP1 in its unphosphorylated form, whereas isoform $\beta$ has undergone a degree of phosphorylation and the $\gamma$ isoform is the fully phosphorylated form. A relatively low expression of 4E-BP1 protein occurred in unoperated control (isoforms $\alpha$ and $\beta$ ) and 1-day (isoform $\beta$ only) ligated glands (Figure 5a). Ligation for 3 days promoted a marked increase in protein expression (sum of all bands for each time point), and at this stage, an increase in the $\gamma$ isoform. This isoform corresponded to an increased phosphorylation status, as antibody staining
}

specific for the phosphorylated form of 4E-BP1 (phospho-4EBP1) also detected this isoform (Figure 5b). From day 5 of ligation onward, all observed 4E-BP1 proteins were in the hyperphosphorylated $\gamma$ state.

Using an anti-4E-BP1 antibody, the 4E-BP1 protein was then localized in progressively longer periods of ligation using immunohistochemistry. In the unoperated control gland, immunostaining appeared strongly in acinar cells (Figure 6a, arrows); however, no staining was seen in ductal structures (Figure 6a, arrow head). After 5 days of ligation, the gland began to appear significantly less compact because of the disappearance of acinar cells, and as a result, ductal structures appeared more numerous and prominent (Figure 6b). After 7 days of ligation, acinar cell staining for 4E-BP1 tended to be localized mostly around the edges of the lobular structures (Figure 6c) and appeared noticeably more diffuse. After 2 weeks of ligation, some acini on the lobule edges still showed low levels of positive immunoreactivity (Figure 6d), whereas no ductal structures were stained.

Activation of autophagy during ligation-induced atrophy. MAP-LC3 is widely used to monitor autophagy by the conversion of LC3-I to LC3-II; the latter is correlated with the number of autophagosomes. On the basis of relative quantities of the LC3-II protein between samples, Figure 7 shows that compared with unoperated control glands (day 0 ), there was increased LC3-II, indicating increased levels of autophagy, which continued throughout the time course of ligation-induced atrophy.

As LC3-II itself is degraded by autophagy, interpreting the results of LC3 immunoblotting is not by itself conclusive. Atg3 has been shown to be involved in the conversion of LC3-I to LC3-II; this protein was measured in the ligation time series to corroborate the activation of autophagy. Immunoblotting showed that there was a marked increase in the expression of Atg3 at day 3 of ligation until day 14 of ligation. This second method of detection confirmed that activation of autophagy occurred around 3 days of ligation and continued throughout ligation.

\section{Discussion}

The results presented in this study reveal atrophy to be a complex process. Although there is considerable cell loss 


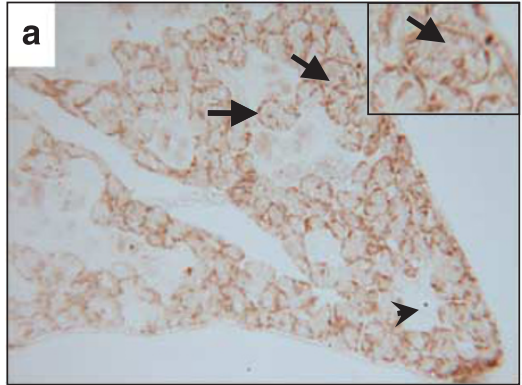

Control X10

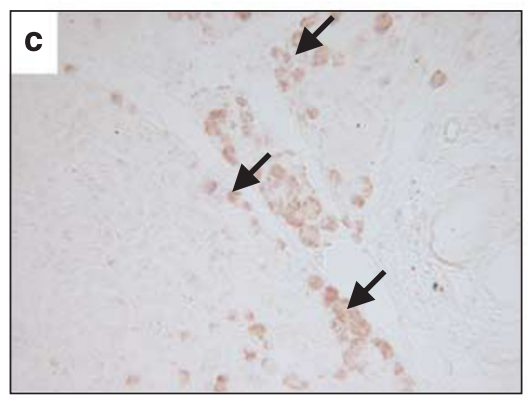

7 Day Ligated $x 10$

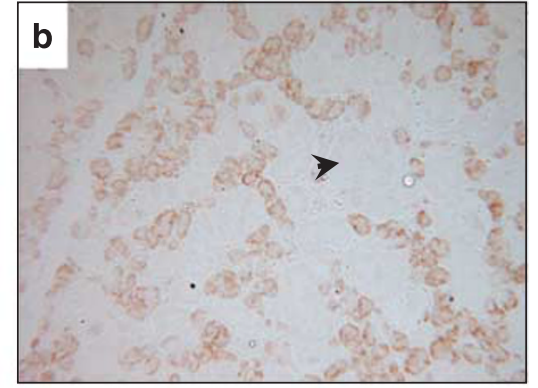

5 Day Ligated X10

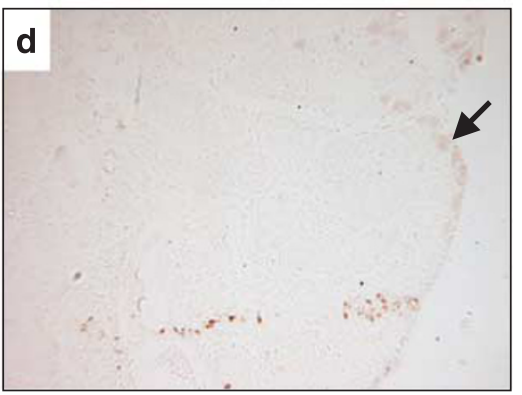

2wk Ligated $x 10$

Figure 6 4E-BP1 immunohistochemistry in the rat submandibular gland. Anti-4E-BP1 antibodies were used to localize 4E-BP1 proteins using wax-embedded sections. (a) Unoperated control gland: immunostaining appeared strongly in acinar cells (arrows; also see inset). No staining was seen in ductal structures (arrow head). (b) 5-day ligated. (c) 7-day ligated. Immunostaining of remaining acinar cells tends to be localized mostly to the edges of lobular structures (arrows). (d) 2-week ligated: some acini at the edge of the lobule still showed low levels of immunoreactivity

a

D0 $\quad$ D1 D3 $\quad$ D5 $\quad$ D7 $\quad$ D9 $\quad$ D14

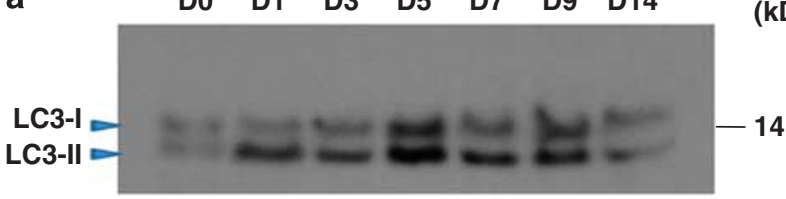

b

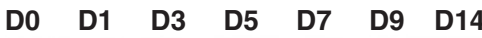

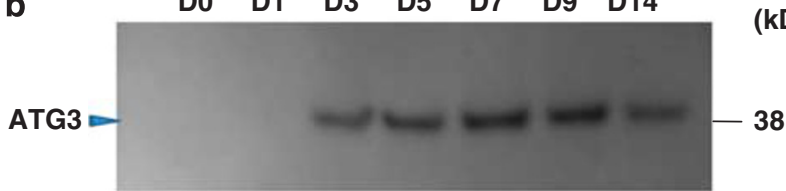

Figure 7 Upregulation of LC3-II and ATG3 protein indicates activation of autophagy during ligation-induced atrophy. (a) Immunoblot showing relative LC3-I and LC3-II protein expression in a ligation time series. (b) Immunoblot showing relative ATG3 protein expression. These blots are representative of two other series of samples

through apoptosis and necrosis and weight loss from the autophagocytic consumption of secretory granules, there is also proliferation and survival. A small but significant proportion of acinar cells survive maintaining transcription of acinarspecific genes, possibly through the activation of mTOR.

When assessing acinar and ductal cell markers in 14-day ligated glands by microarray analyses, a clear difference existed between granular duct-associated genes and genes specific to acinar cells. Ductal genes including kallikrein 3, 7, 10 and TON, which are highly expressed in normal glands (within the top $1 \%$ of total glandular gene expression), were reduced to background levels. TON was chosen as a representative ductal cell marker, and Q-RT-PCR confirmed the microarray results. Levels of the corresponding protein were also found to be almost completely abolished. Acinarspecific genes, in contrast to ductal genes, showed few significant changes by microarray analysis, despite the loss of most acinar cells. Among the list (Table 2) of acinar cell markers that showed no change in gene expression were AQP5, a water channel shown to be localized predominantly to the apical membrane ${ }^{19}$ and crucial to salivary secretion, ${ }^{22}$ and SMR2, a major secretory glutamine/glutamic acid-rich protein that has been localized previously to acinar cells in the rat submandibular gland using in situ hybridization. ${ }^{20}$ Although a reduction in expression of these acinar cell markers was seen when using Q-RT-PCR, in terms of cycle threshold values, mRNA expression for both $A Q P 5$ and SMR2 remained well above background levels. Conventional staining of histological sections has suggested that few if any acinar cells remain. However, using an indirect staining of myoepithelial cells surrounding acini, we estimate that $10 \%$ of acinar cells are still present. Others have also shown that these are functional cells with normal intracellular responses to autonomimetics. ${ }^{23}$ When taking into account the large loss of acinar cells, this would suggest that the remaining acinar cells still have a robust transcription of secretory proteins. However, although the remaining acinar cells seemed to be transcriptionally active, immunostaining showed that at around day 7 in ligation-induced atrophy, anti-AQP5 reactivity was greatly reduced. Similar results were obtained for SMR2, mucin and carbonic anhydrase VI (results not shown). 
The loss of weight within the first week of ligation is a reflection of secretory granule loss and cell loss. Cell loss is likely to be a mixture of necrosis and apoptosis, as rates of both are relatively high after 3 days of ligation. ${ }^{5}$ The role of autophagy in causing cell death is still unclear, ${ }^{24}$ as there is considerable loss of secretory granules from acinar and ductal cells by day 5 , but whereas acinar cells die, ductal cells seem to proliferate as dedifferentiated ducts. ${ }^{5}$ Electron microscopy has previously detected autophagosomal vesicles in ligationinduced atrophy of the rat, although the exact time points were not reported. ${ }^{10}$ Biochemical analyses also indicate a $50 \%$ loss of ductal kallikreins after just 2 days of ligation. ${ }^{25}$ The ratelimiting step in autophagic processes is autophagosome formation, which involves $\sim 20$ autophagy-related (Atg) proteins. One of these proteins, Atg8 (LC3-I), can be lipidated with PE to form LC3-II, and used as an autophagosome marker. ${ }^{26}$ Although electron microscopical evidence of autophagy in salivary glands after ligation ${ }^{27,28}$ has been presented before, the roles of autophagy in salivary glands using this marker have not yet been explored.

The PI3K/Akt/mTOR pathway has recently been reported to reduce apoptosis in various tissues, ${ }^{29,30}$ and as a result, may contribute to the survival of the residual acinar cells seen in the 14-day ligated submandibular glands. mTOR through various downstream effectors mediates a balance between cell growth and protein degradation. In yeast, activated TOR has been shown to increase protein synthesis and reduce protein catalysis. ${ }^{31}$ In the pancreas, PI3K/Akt activation through IGF-1-mediated stimulation was found to have a critical role in the regeneration of pancreatic acini after resection. ${ }^{32}$ On the basis of evidence presented in these studies, in atrophic SMG, in which there is an arrest in cellular growth and proliferation, as well as a loss of certain proteins, it may be expected that there might also be a loss of PI3K/Akt/mTOR activation. However, in the 2-week atrophic SMG, expression of insulin-like growth factor I (AA945615) and IGFbp4 were both found to be upregulated (approximately four-fold), indicating activation of the PI3K/Akt/mTOR pathway. In this situation, it is likely that PI3K/Akt/mTOR activation may function to reduce or minimize apoptosis and promote cell survival. This is supported by a study carried out by Limesand et al. ${ }^{30}$ showing that a significant level of apoptosis detected in the salivary glands of FVB mice after $\gamma$-irradiation of the head and neck can be suppressed in transgenic mice expressing an activated mutant of Akt (myr-Akt1). Furthermore, an intravenous injection of IGF-1 stimulated the activation of endogenous Akt in salivary glands in vivo, and a single injection of IGF-1 before exposure to $\gamma$-radiation diminishes salivary acinar cell apoptosis. ${ }^{33}$

As there seemed to be activation of the PI3K/Akt/mTOR pathway, but a block in translation with ligation-induced atrophy, control at the level of the translational machinery was examined in more detail. This is a tightly controlled system that is composed of eukaryotic initiation factors, and controls the recruitment of ribosomes to mediate capdependent translation. ${ }^{14}$ Accordingly, this cap-dependent translation machinery is functionally controlled by mTOR through the phosphorylation of its downstream substrates, 4E-BPs and S6Ks. One of these substrates, 4E-BP1, encodes a binding protein that negatively regulates the initiation of translation. More specifically, 4E-BP1 is a suppressor of the translation initiation factor elF-4E, which itself recognizes the cap structure present at the $5^{\prime}$ end of all nuclear-transcribed eukaryotic mRNAs. Owing to the recognized importance of this binding protein in controlling initiation of translation, 4E-BP1 protein expression was investigated at different stages of ligation by western blotting using an anti-4E-BP1 antibody. Western blotting analysis revealed that 4E-BP1 was consistently expressed throughout the ligation time series, with an increase in absolute protein quantities seen at day 3 onwards. More importantly, 4E-BP1 became hyperphosphorylated, as indicated by band shifts at day 3 onwards of ligation, and this was confirmed using anti-phospho-Thr37/464E-BP1 antibody (Figure 5b). Overall, the results confirmed that the mTOR pathway was activated and presumably translation initiated. Furthermore, using immunohistochemistry to localize 4E-BP1, the hyperphosphorylated form was localized to the periphery of the 2-week atrophic gland (Figure $6 \mathrm{~d}$ ), suggesting that activation of mTOR protects a sub-population of acinar cells. This is supported by AB/PAS staining in which secretory glycoproteins (Figure $1 \mathrm{~h}$ ) in the granules can still be seen in the periphery of the gland, indicating that these acinar cells may still be functional. Similar observations were made in a study of diabetes mellitusassociated pancreatic atrophy, in which, although a decrease in the production of digestive proteins was observed, there was an increase in the phosphorylation of 4E-BP1. ${ }^{34}$

Evidence from our study leads us to hypothesize that during progressive ligation-induced atrophy of the rat submandibular gland, there is activation of both mTOR and autophagic pathways at the same time point in different acinar populations. If mTOR activation inhibits the autophagosomal lysosomal pathway, ${ }^{35}$ then continued 4E-BP1 expression in addition to $A B / P A S$ reactivity indicates surviving acinar cells. The existence of acinar cells within ligated glands that are still transcriptionally active suggests that mTOR activation may be promoting anti-apoptotic effects and aiding cell survival.

\section{Materials and Methods}

Antibodies. Anti-4E-BP1 (Y329) (1:2000 for western blotting) was obtained from Abcam (Abcam plc, Cambridge, UK), anti-phospho-Thr37/46-4E-BP1 (9459) (1:1000 for western blotting) antibody was from New England Biolabs Inc. (Hitchin, Hertfordshire, UK), anti-LC3 (2775S) (1:250 for western blotting) antibody was from New England Biolabs Inc., anti-AQP5 (sc-9891) antibody was from Santa Cruz Biotechnology Inc. (Santa Cruz, CA, USA) and anti-smooth muscle actin (clone 1A4) was from Dako Ltd (Ely, UK). Secondary antibodies included polyclonal goat anti-mouse immunoglobulin-HRP (P0447), polyclonal goat antirabbit immunoglobulin-HRP (P0448) and polyclonal rabbit anti-goat immunoglobulin-HRP (P0160) from Dako Ltd, as well as anti-goat Alexa 568 from Invitrogen Ltd (Paisley, UK).

Duct ligation surgery and samples. All experimental and killing procedures were conducted with the approval of the local research ethics committee under a Home Office license. A total of 20 adult male rats of Wistar (Harlan) strain $(250-350 \mathrm{~g})$ were anesthetized with ketamine/xylazine I.P. $(75+15 \mathrm{mg} / \mathrm{kg}$ I.P. each), and the main excretory ducts of the right submandibular and sublingual glands were carefully dissected using an intra-oral approach. ${ }^{25}$ The ducts were ligated $5 \mathrm{~mm}$ posterior to the ductal orifice (without including the chorda lingual nerve) using a metal microclip (SLS, Vitalitec International, Domalain, France). The incision in the floor of the mouth was closed with an 8-0 Ethilon suture (Johnson and Johnson Intl, Brussels, Belgium). Animals were allowed to recover from anesthesia in a cage maintained in a warm room. Aseptic conditions were used throughout the surgical procedure of duct ligation to 
reduce the risk of infection. Submandibular gland samples collected for analysis were as follows: control $(n=3), 1$-day ligated $(n=3)$, 3-day ligated $(n=3), 5$-day ligated $(n=3)$, 7-day ligated $(n=3)$, 9-day ligated $(n=3)$ and 14-day ligated $(n=3)$. Control glands were obtained from completely unoperated rats. At the end of experiments, submandibular glands were removed and tissue was fixed in formol sucrose overnight. Rats were killed by an overdose of pentobarbitone.

Histochemical staining of tissue samples. Tissue was embedded in wax and $5-\mu \mathrm{m}$-thick sections were cut and mounted on slides. The secretory granules inside the acinar cells were identified by Alcian blue/periodic acid-Schiff's (AB/PAS) staining. Granular ductal kallikreins were stained using DMAB.

Isolation of RNA, reverse transcription and cDNA preparation. Total RNA was isolated from $\sim 30 \mathrm{mg}$ of liquid nitrogenpreserved submandibular gland tissue and homogenized in $600 \mu \mathrm{l}$ RNA-Bee (AMS Biotechnology (Europe) Ltd, Abingdon, UK) using a 7-ml glass tissue grinder (Zinsser Analytic Ltd, Maidenhead, UK). The RNeasy Mini Kit (Qiagen Ltd, Crawley, UK) was used for RNA isolation according to the manufacturer's protocol. The RNA yield and the ratio of absorbance at 260-280 nm (A260/A280 ratio) and 260-230 nm (A260/A280 ratio) were measured using a NanoDrop ND-1000 Spectrophotometer (NanoDrop Technologies, Wilmington, DE, USA). The integrity of isolated total RNA was assessed using an RNA 6000 Nano LabChip Kit using the Agilent 2100 Bioanalyzer (Agilent Technologies, South Queensferry, UK). Precipitated RNA was resuspended in $50 \mu \mathrm{LDEPC}$-treated water and $1 \mu \mathrm{g}$ of RNA was reverse transcribed with $200 \mathrm{U}$ Superscript III Reverse Transcriptase (Invitrogen Ltd) for $60 \mathrm{~min}$ at $50^{\circ} \mathrm{C}$ using Oligo-dT in $20 \mu$ l volume. All reverse transcription reactions were carried out in parallel to avoid introducing experimental variation. After reverse transcription

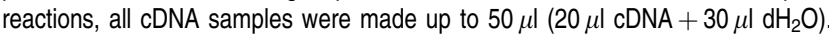
Sample aliquots were then removed and diluted 1:100 in preparation for use in $\mathrm{Q}-\mathrm{RT}$-PCR reactions.

DNA microarray analysis. The labeled targets for Affymetrix DNA microarray analysis were prepared according to the manufacturer's instructions. Rat Genome 2302.0 GeneChip microarray was hybridized with the targets at $45^{\circ} \mathrm{C}$ for $16 \mathrm{~h}$ and then washed and stained using the GeneChip Fluidics station according to the manufacturer's instructions. DNA chips were scanned using the GeneChip scanner, and the images obtained were processed by the GeneChip Operating Software (GCOS) (version 3.2) (Affymetrix, High Wycombe, UK) incorporating the MAS 5.0 algorithm for background correction, normalization and summarization of probe sets.

Quantitative RT-PCR. For Q-RT-PCR, the PCR sample comprised $4 \mu \mathrm{l}$ diluted cDNA, Quantace SYBR green SensiMix (Quantace Ltd, London, UK) and $5 \mu \mathrm{M}$ each of forward and reverse primers in a total volume of $20 \mu \mathrm{l}$. Q-RT-PCR was carried out using the Corbett Rotor-Gene 6000 (Qiagen Ltd) in a 72-well rotor Amplifications were performed starting with an enzyme activation/template denaturation step of $95^{\circ} \mathrm{C}$ for $10 \mathrm{~min}$, followed by 40 cycles of $95^{\circ} \mathrm{C}$ for $15 \mathrm{~s}$ and $60^{\circ} \mathrm{C}$ for $30 \mathrm{~s}$. Melt-curve analysis was carried out to assess product specificity. All runs were carried out in duplicate and included the housekeeping gene ubiquitin (UBC) as an internal control. Samples were normalized to UBC, giving arbitrary values representing a ratio of experimental to internal control results. Results are expressed as relative mRNA levels.

Preparation of tissue homogenates for western blotting. Tissue specimens stored at $-80^{\circ} \mathrm{C}$ were homogenized in 24 volumes (wt/vol) of ice-cold homogenization buffer ( $1 \%$ Triton X-100, $1 \mathrm{mM}$ EDTA, and a $1 \% \mathrm{v} / \mathrm{v}$ dilution of protease inhibitor cocktail set 1 (Merck Chemicals Ltd, Nottingham, UK) using an Ultra-Thurrax homogenizer (IKA Labortechnik, Staufen, Germany). The homogenate was then passed 8-10 times through a 29-G needle and cellular debris was removed by centrifugation at $600 \mathrm{~g}$ for $10 \mathrm{~min}$ at $4^{\circ} \mathrm{C}$. SDS-PAGE of samples was carried out (NuPAGE Novex BIS-TRIS 12-14\% gel; Invitrogen Ltd). Proteins resolved by electrophoresis were then electroblotted onto $0.45 \mu \mathrm{m}$ nitrocellulose membranes (Anderman and Co., Kingston-Upon-Thames, UK). Immunoblotting was performed as described previously by Carpenter et al. ${ }^{36}$ Primary antibody dilutions were as described in the 'Antibodies' section.

Immunohistochemistry on tissue sections. Tissue sections were first dewaxed and then incubated in a solution of $3 \%$ hydrogen peroxide to inhibit endogenous peroxidase. After a brief wash in distilled water, sections were incubated at $95^{\circ} \mathrm{C}$ for $10 \mathrm{~min}$ in citric acid, $\mathrm{pH} 6.0$. After being washed in phosphatebuffered saline (PBS; $0.1 \mathrm{M}$ ), sections were incubated with normal goat serum (Dako Ltd; $1: 5$ dilution in PBS) to avoid nonspecific binding of the primary antibody. To investigate the presence of smooth muscle actin, tissue sections were incubated with an antismooth muscle actin antibody at a dilution of $1: 100$ in PBS. The secondary antibody was an HRP (horseradish peroxidase)-linked polyclonal goat anti-mouse antibody ( $1: 200$ dilution in PBS). The sections were then reacted and visualized using diaminobenzidine tetrahydrochloride $(0.5 \mathrm{mg} / \mathrm{ml})$ with $0.1 \%$ hydrogen peroxide and counterstained with Mayer's hematoxylin. To investigate the presence of $4 \mathrm{E}-\mathrm{BP} 1$, the same protocol was followed, using an anti-4E-BP1 antibody (1:100) and an anti-polyclonal goat anti-rabbit secondary antibody $(1: 200)$. No counterstain was used to visualize 4E-BP1.

Cell preparation for immunocytochemistry. A portion of the gland was minced and digested with collagenase $(0.5 \mathrm{mg} / \mathrm{ml}$; Worthington Biochemical, Reading, UK) as described previously. ${ }^{36}$ The tissue was incubated at $37^{\circ} \mathrm{C}$ for $45 \mathrm{~min}$ in the presence of $100 \%$ oxygen and then centrifuged $(1000 \mathrm{~g})$. The cells were resuspended in $10 \mathrm{ml}$ fresh medium without collagenase and incubated in the presence of oxygen at $37^{\circ} \mathrm{C}$ for another $30 \mathrm{~min}$.

Immunocytochemistry for confocal laser microscopy. After incubation in collagenase-free buffer, cells were washed with PBS and then fixed in $100 \%$ methanol for $10 \mathrm{~min}$ at room temperature. After a brief wash with PBS, cells were sequentially incubated in blocking buffer with various concentrations of bovine serum albumin (BSA; 0.1 and $1 \% \mathrm{w} / \mathrm{v}$ ), followed by goat anti-AQP5 monoclonal antibody (1:50 dilution). Negative controls were incubated with $1 \%$ BSA blocking buffer and secondary antibody only. After washing with PBS, a secondary fluorescent antibody (anti-goat Alexa 568, 1:2000) was added to the cells. Finally, the cells were washed and mounted on slides with MOWIOL solution. Having carried out immunocytochemistry, acinar units were analyzed by laser confocal microscopy. Optical sections $(1 \mu \mathrm{m})$ were captured at various depths, projected as a three-dimensional image and color-coded according to the depth of the field. This provided detailed information on the location of the AQP5 protein within acinar cell units.

Statistical analysis. Gland weight results presented in the text were expressed as mean \pm S.E.M., and were statistically compared by paired Student's $t$-test. $P=<0.05$ was considered statistically significant. The REST statistical model ${ }^{37}$ uses a pairwise fixed reallocation randomization test (statistical significance $<0.05$ ) and was used where appropriate.

\section{Conflict of interest}

The authors declare no conflict of interest.

Acknowledgements. We gratefully acknowledge funding by the Wellcome trust and kind gifts of antibodies from Ms Raghad Aldabbagh (King's College London, UK). Authors would also like to acknowledge Katherine Paterson for guidance on histological techniques.

1. Proctor GB, Carpenter GH. Regulation of salivary gland function by autonomic nerves. Auton Neurosci-Basic and Clinical 2007; 133: 3-18.

2. Garrett JR, Suleiman AM, Anderson LC, Proctor GB. Secretory responses in granular ducts and acini of submandibular glands in vivo to parasympathetic or sympathetic- nerve stimulation in rats. Cell Tissue Res 1991; 264: 117-126.

3. Proctor GB. Secretory protein synthesis and constitutive (vesicular) secretion by salivary glands. In: Garrett JR, Ekstrom J, Anderson LC (eds). Glandular Mechanims of Salivary Secretion. Karger: Basel, 1998, pp 73-88.

4. Cummins M, Dardick I, Brown D, Burford-Mason A. Obstructive sialadenitis: a rat model. J Otolaryngol 1994; 23: 50-56.

5. Takahashi S, Nakamura S, Suzuki R, Islam N, Domon T, Yamamoto T et al. Apoptosis and mitosis of parenchymal cells in the duct-ligated rat submandibular gland. Tissue Cell 2000; 32: 457-463.

6. Harrison JD, Fouad HM, Garrett JR. The effects of ductal obstruction on the acinar cells of the parotid of cat. Arch Oral Biol 2000; 45: 945-949.

7. Anderson DJ, Hector MP. Periodontal mechanoreceptors and parotid secretion in animals and man. J Dent Res 1987; 66: 518-523.

8. Proctor GB. Effects of autonomic denervations on protein secretion and synethesis by salivary glands. In: Garrett JR, Ekstrom J, Anderson LC (eds). Neural Mechanisms of Salivary Gland Secretion. Karger: Basel, 1999, pp 150-165. 
9. Garrett JR. Effects of autonomic denervations on parenchymal structure and nerves in salivary glands. In: Garrett JR, Ekstrom J, Anderson LC (eds). Neural Mechanisms of Salivary Gland Secretion. Karger: Basel, 1999, pp 131-149.

10. Tamarin A. Submaxillary gland recovery from obstruction. II. Electron microscopic alterations of acinar cells. J Ultrastruct Res 1971; 34: 288-302.

11. Tamarin A. Submaxillary gland recovery from obstruction. I. Overall changes and electron microscopic alterations of granular duct cells. J Ultrastruct Res 1971; 34: 276-287.

12. Datta K, Bellacosa A, Chan TO, Tsichlis PN. Akt is a direct target of the phosphatidylinosito 3-kinase. Activation by growth factors, $\mathrm{v}$-src and $\mathrm{v}$-Ha-ras, in Sf9 and mammalian cells. J Biol Chem 1996; 271: 30835-30839.

13. Fingar DC, Blenis J. Target of rapamycin (TOR): an integrator of nutrient and growth factor signals and coordinator of cell growth and cell cycle progression. Oncogene 2004; 23: 3151-3171.

14. Wang $X$, Proud CG. The mTOR pathway in the control of protein synthesis. Physiology (Bethesda) 2006; 21: 362-369.

15. Mieulet V, Roceri M, Espeillac C, Sotiropoulos A, Ohanna M, Oorschot V et al. S6 kinase inactivation impairs growth and translational target phosphorylation in muscle cells maintaining proper regulation of protein turnover. Am J Physiol Cell Physiol 2007; 293: C712-C722.

16. Pause A, Belsham GJ, Gingras AC, Donze O, Lin TA, Lawrence Jr JC et al. Insulindependent stimulation of protein synthesis by phosphorylation of a regulator of $5^{\prime}$-cap function. Nature 1994; 371: 762-767.

17. Hand AR, Ball WD. Ultrastructural immunocytochemical localization of secretory proteins in autophagic vacuoles of parotid acinar cells of starved rats. J Oral Pathol 1988; 17: 279-286.

18. Ohsumi Y. Molecular dissection of autophagy: two ubiquitin-like systems. Nat Rev Mol Cell Biol 2001; 2: 211-216.

19. Matsuzaki T, Suzuki T, Koyama H, Tanaka S, Takata K. Aquaporin-5 (AQP5), a water channel protein, in the rat salivary and lacrimal glands: immunolocalization and effect of secretory stimulation. Cell Tissue Res 1999; 295: 513-521.

20. Rosinski-Chupin I, Rougeot C, Courty Y, Rougeon F. Localization of mRNAs of two androgen-dependent proteins, SMR1 and SMR2, by in situ hybridization reveals sexual differences in acinar cells of rat submandibular gland. J Histochem Cytochem 1993; 41 : 1645-1649.

21. Takahashi S, Kohgo T, Nakamura S, Arambawatta AK, Domon T, Yamamoto T et al. Biological behavior of myoepithelial cells in the regeneration of rat atrophied sublingua glands following release from duct ligation. J Mol Histol 2005; 36: 373-379.

22. Ma T, Song Y, Gillespie A, Carlson EJ, Epstein CJ, Verkman AS. Defective secretion of saliva in transgenic mice lacking aquaporin-5 water channels. J Biol Chem 1999; 274: 20071-20074.

23. Liu $P$, Scott J, Smith PM. Intracellular calcium signalling in rat parotid acinar cells that lack secretory vesicles. Biochem J 1998; 330 (Pt 2): 847-852.
24. Kroemer G, Levine B. Autophagic cell death: the story of a misnomer. Nat Rev Mol Cell Biol 2008; 9: 1004-1010

25. Osailan SM, Proctor GB, McGurk M, Paterson KL. Intraoral duct ligation without inclusion of the parasympathetic nerve supply induces rat submandibular gland atrophy. Int $J$ Exp Pathol 2006; 87: 41-48.

26. Mizushima N, Yoshimori T. How to interpret LC3 immunoblotting. Autophagy 2007; 3 : 542-545.

27. Harrison JD, Fouad HM, Garrett JR. Variation in the response to ductal obstruction of feline submandibular and sublingual salivary glands and the importance of the innervation. J Oral Pathol Med 2001; 30: 29-34

28. Tamarin A. Secretory cell alterations associated with submaxillary gland duct ligation. In: Schneyer CA, Schneyer LH (eds). Secretory Mechanisms of Salivary Glands. Academic: New York, 1992, pp 220-237.

29. Castedo M, Ferri KF, Kroemer G. Mammalian target of rapamycin (mTOR): pro- and antiapoptotic. Cell Death Differ 2002; 9: 99-100.

30. Limesand KH, Schwertfeger KL, Anderson SM. MDM2 is required for suppression of apoptosis by activated Akt1 in salivary acinar cells. Mol Cell Biol 2006; 26: 8840-8856.

31. Arsham AM, Neufeld TP. Thinking globally and acting locally with TOR. Curr Opin Cell Biol 2006; 18: 589-597.

32. Watanabe H, Saito H, Rychahou PG, Uchida T, Evers BM. Aging is associated with decreased pancreatic acinar cell regeneration and phosphatidylinositol 3-kinase/Akt activation. Gastroenterology 2005; 128: 1391-1404

33. Limesand KH, Said S, Anderson SM. Suppression of radiation-induced salivary gland dysfunction by IGF-1. PLoS One 2009; 4: e4663.

34. Patel R, Atherton $P$, Wackerhage $H$, Singh J. Signaling proteins associated with diabeticinduced exocrine pancreatic insufficiency in rats. Ann NY Acad Sci 2006; 1084: 490-502.

35. Pattingre S, Espert L, Biard-Piechaczyk M, Codogno P. Regulation of macroautophagy by mTOR and Beclin 1 complexes. Biochimie 2008; 90: 313-323.

36. Carpenter GH, Proctor GB, Ebersole LE, Garrett JR. Secretion of IgA by rat parotid and submandibular cells in response to autonomimetic stimulation in vitro. Int Immunopharmacol 2004; 4: 1005-1014.

37. Pfaffl MW, Horgan GW, Dempfle L. Relative expression software tool (REST) for groupwise comparison and statistical analysis of relative expression results in real-time PCR Nucleic Acids Res 2002; 30: e36.

Cell Death and Disease is an open-access journal published by Nature Publishing Group. This article is licensed under a Creative Commons Attribution-Noncommercial-No Derivative Works 3.0 License. To view a copy of this license, visit http:// creativecommons.org/licenses/by-nc-nd/3.0/ 